\title{
The Adenylate Cyclase (CyaA) Toxin from Bordetella pertussis Has No Detectable Phospholipase A (PLA) Activity In Vitro
}

\author{
Alexis Voegele $\left.{ }^{1,2}{ }^{(}\right)$, Mirko Sadi $^{1}$, Dorothée Raoux-Barbot ${ }^{1}$, Thibaut Douché ${ }^{3}{ }^{(D)}$, \\ Mariette Matondo ${ }^{3}$, Daniel Ladant ${ }^{1, *}$ and Alexandre Chenal ${ }^{1, *}$ (D) \\ 1 Chemistry and Structural Biology Department, Institut Pasteur, UMR CNRS 3528, CEDEX 15, 75724 Paris, \\ France; alexis.voegele@pasteur.fr (A.V.); mirko.sadi@outlook.de (M.S.); \\ dorothee.raoux-barbot@pasteur.fr (D.R.-B.) \\ 2 Université Paris Diderot Paris VII, 75013 Paris, France \\ 3 Mass Spectrometry for Biology Unit, Proteomics Platform, Institut Pasteur, USR CNRS 2000, CEDEX 15, \\ 75724 Paris, France; thibaut.douche@pasteur.fr (T.D.); mariette.matondo@pasteur.fr (M.M.) \\ * Correspondence: daniel.ladant@pasteur.fr (D.L.); alexandre.chenal@pasteur.fr (A.C.)
}

Received: 28 January 2019; Accepted: 11 February 2019; Published: 13 February 2019

check for updates

\begin{abstract}
The adenylate cyclase (CyaA) toxin produced in Bordetella pertussis is the causative agent of whooping cough. CyaA exhibits the remarkable capacity to translocate its N-terminal adenyl cyclase domain (ACD) directly across the plasma membrane into the cytosol of eukaryotic cells. Once translocated, calmodulin binds and activates ACD, leading to a burst of cAMP that intoxicates the target cell. Previously, Gonzalez-Bullon et al. reported that CyaA exhibits a phospholipase A activity that could destabilize the membrane to facilitate ACD membrane translocation. However, Bumba and collaborators lately reported that they could not replicate these results. To clarify this controversy, we assayed the putative PLA activity of two CyaA samples purified in two different laboratories by using two distinct fluorescent probes reporting either PLA2 or both PLA1 and PLA2 activities, as well as in various experimental conditions (i.e., neutral or negatively charged membranes in different buffers.) However, we could not detect any PLA activity in these CyaA batches. Thus, our data independently confirm that CyaA does not possess any PLA activity.
\end{abstract}

Keywords: adenylate cyclase toxin; CyaA toxin; bordetella pertussis; phospholipase A; fluorescence

Key Contribution: The present communication aims at clarifying the controversy on the recently reported PLA activity of CyaA, by using fluorescent probes reporting either PLA2 or both PLA1 and PLA2 activities in various experimental conditions. We could not detect PLA activity in two CyaA samples purified in two different laboratories, confirming that CyaA does not possess any PLA activity.

\section{Introduction}

The adenylate cyclase (CyaA or ACT) toxin is secreted by Bordetella pertussis, the causative agent of whooping cough. The CyaA toxin is one of the major virulence factors produced by $B$. pertussis and is involved in the early stages of respiratory tract colonization [1-5]. CyaA invades eukaryotic target cells, where it is activated by calmodulin (CaM) to produce supra-physiological cAMP concentrations. It is a 1706-residue long protein that belongs to the Repeat-in-ToXin (RTX) family of cytolysins [6-10]. CyaA is a multi-domain protein [11,12], harboring from the N-to C-terminus, that has (i) a calmodulin-activated catalytic domain, ACD, located in the first 364 N-terminal residues [13-15]; (ii) a translocation region (TR, residues 365 to 527) that is essential for ACD translocation into target 
cells [16-19]; (iii) a hydrophobic region (HR, residues 528 to 710) that inserts into the cell membrane and makes cation-selective pores leading to cell lysis [10,20,21]; (iv) an acylation region (AR, residues 711 to 1005) that contains two post-translational acylation sites on K860 and K983 [22-24] (modifications are required for the proper refolding and activity of CyaA) $[5,12,22,23,25]$; and (v) a C-terminal domain (RD, residues 1006 to 1706) made of about 40 copies of calcium-binding RTX motifs [8-10,26] that are required for RD and subsequently CyaA folding [27-35] and interaction with the CyaA cell receptor, CD11b/CD18 [36,37]. CyaA uses an original intoxication mechanism: once secreted by B. pertussis, it invades eukaryotic cells through a unique molecular mechanism that involves a direct translocation of its ACD catalytic domain across the plasma membrane. Yet, the molecular mechanisms of this unique entry process remain largely unknown.

Recently, H. Ostolaza et al. reported that CyaA exhibits a phospholipase A (PLA) activity [38,39] that is involved in destabilizing the lipid bilayer to facilitate ACD translocation across the plasma membrane. These results were contested by Bumba et al., who subsequently reported that CyaA has no PLA1 activity and showed that the two residues Ser606 and Asp1079 claimed to be critical for the putative PLA activity of CyaA, were not involved in CyaA translocation [40].

To clarify this controversy, we examined the PLA activity of two purified CyaA samples, one from our laboratory $\left(\mathrm{CyaA}_{I P}\right)$ and the second provided by Ostolaza's team ( $\left.\mathrm{CyaA}_{\mathrm{UBC}}\right)$. Mass spectrometry data revealed that both CyaA batches were devoid of contaminating E. coli phospholipase. Using two distinct fluorescent probes of PLA activity, PED6 (specific to PLA2 activity) and B3781 (for both PLA1 and PLA2 activities), we could not detect any PLA activity in these CyaA preparations. This unambiguously indicates that CyaA has no detectable phospholipase A activity in vitro, which agrees with the prior results of Bumba et al. [40]. We discuss potential artifacts that might have blurred the conclusions of the Ostolaza team.

\section{Results}

\subsection{Characterization of the $C y a A_{I P}$ and $C y a A_{U B C}$ Preparations}

The CyaA preparations used in this study, $C_{\text {a }} \mathrm{A}_{\mathrm{IP}}$ from our laboratory and $\mathrm{Cya}_{\mathrm{UBC}}$ from Ostolaza's team, were recombinantly produced in E. coli and purified using previously described protocols $[12,38,41]$. Both protein samples showed potent hemolytic activity and cell invasive capacities when tested on sheep erythrocytes (data not shown). Proteomic analysis of the CyaA batches was then performed to determine the extent of contamination of the samples by E. coli host phospholipases. The total E. coli contaminant proteins from both CyaA batches were identified using liquid chromatography-mass spectrometry (LC-MS/MS) (see supporting files: CyaA_IP_MS_result and CyaA_UBC_MS_result). The E. coli phospholipases (protein references EC 3.1.1.32 and EC 3.1.1.4) were not detected among contaminants in both CyaA samples. A lysophospholipase (EC 3.1.1.5), however, was identified in $\mathrm{Cya}_{\mathrm{UBC}}$ but at very low abundance (see supporting file CyaA_UBC_MS_result). Hence, we can conclude that both $\mathrm{CyaA}_{I P}$ and $\mathrm{CyaA}_{\mathrm{UBC}}$ are devoid of any contaminating PLA from E. coli.

\subsection{PLA Activity Measurements as Monitored with the PED6 Fluorescent Probe}

We first investigated PLA activity using a fluorescent probe, PED6, which is specific for PLA2 activity. In PED6, a 4,4-Difluoro-5,7-Dimethyl-4-Bora-3a,4a-Diaza-s-Indacene group linked to the acyl chain is quenched with a 2,4-Dinitrophenyl group linked to the lipid headgroup. The cleavage of PED6 using a PLA2 enzyme is monitored by the fluorescent recovery of the indacene group (excitation at $480 \mathrm{~nm}$; emission at $490-650 \mathrm{~nm}$; full spectra are shown in supplementary Figure S1). Figure 1A shows a time course recording of the fluorescence emission at $515 \mathrm{~nm}\left(\mathrm{~F}_{515}\right)$ of PED6 in the presence of LUV (DOPC:PED6 at a 8:2 molar ratio) in buffer alone or after addition of various proteins. Further, the addition of $10 \mathrm{nM}$ crotoxin, a neurotoxin from Crotalus durissus terrificus [42,43] with a potent PLA activity, induced a large increase (up to 15 fold) in fluorescence emission (Figure 1A,B, black trace). 
In contrast, no detectable PED6 fluorescence changes were observed after the addition of $10 \mathrm{nM} \mathrm{BSA}$, a control protein lacking PLA activity, or, more importantly, of $10 \mathrm{nM}$ of either $\mathrm{Cya}_{\mathrm{IP}}$ or $\mathrm{Cya}_{\mathrm{UBC}}$ (Figure 1A, orange and red traces, respectively). This indicates that the two CyaA proteins do not exhibit PLA2 activity. Figure 1B shows the same kinetics of fluorescence emission after normalization to the fluorescence intensity at a time of zero. While a high increase in fluorescence is observed with crotoxin (black trace), the fluorescence intensity variations observed with the two CyaA samples over a 30 min course are within a few percent of the initial $\mathrm{F}_{515}$ (Figure 1B, inset) and are essentially indistinguishable from that recorded with the buffer alone, or upon addition of BSA or of $60 \mathrm{mM}$ urea (corresponding to the residual urea concentration obtained after addition of $10 \mathrm{nM}$ CyaA proteins, as the toxins were stored in concentrated urea solutions). These data unambiguously indicate that the CyaA samples had no detectable PLA2 activity in these conditions.
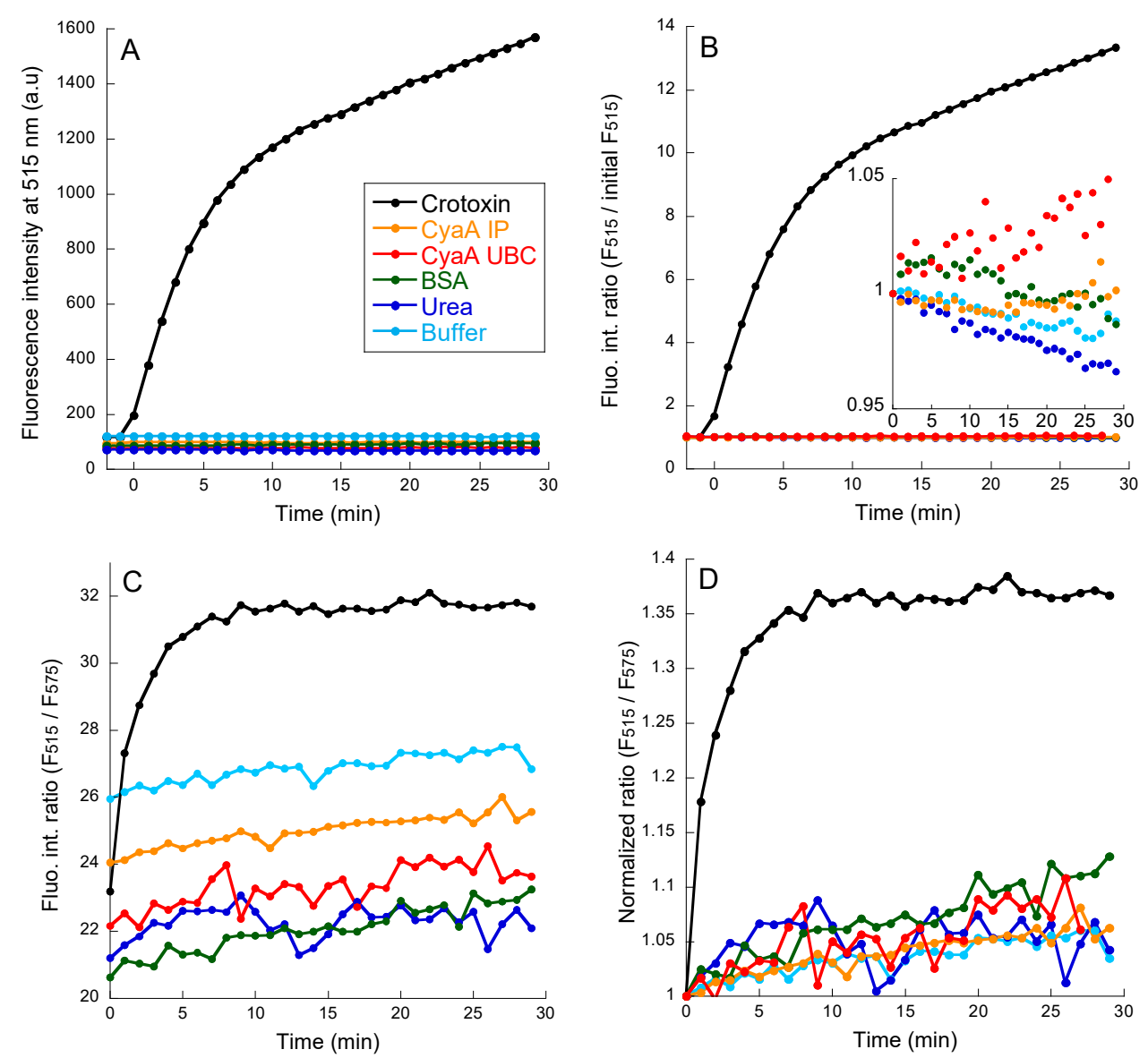

Figure 1. The kinetics of fluorescence changes of PED6 incorporated in DOPC:PED6 8:2 LUV (data from Figure S1). The time 0 min corresponds to the addition of the following samples: buffer (light blue), urea (dark blue), BSA (green), Crotoxin (black), $\mathrm{CyaA}_{\mathrm{IP}}$ (orange), and $\mathrm{CyaA}_{\mathrm{UBC}}$ (red). (A) Increase of fluorescence emission intensity at $515 \mathrm{~nm}$. (B) Ratio of fluorescence intensity at $515 \mathrm{~nm}, \mathrm{~F}_{515}$, at time $\mathrm{t}$ normalized by initial fluorescence at $515 \mathrm{~nm}$. Inset shows same data with an expanded $Y$-axis (from 0.95 and 1.05). (C) Ratio of fluorescence intensity at $515 \mathrm{~nm}$ over fluorescence intensity at $575 \mathrm{~nm}$ : $\mathrm{F}_{515} / \mathrm{F}_{575}$. (D) The $\mathrm{F}_{515} / \mathrm{F}_{575}$ values are normalized to the initial $\mathrm{F}_{515} / \mathrm{F}_{575}$ value at 0 min (see methods for details).

Figure 1C,D show a different representation of the same data, plotted as relative ratio of fluorescence intensity at $515 \mathrm{~nm}$ over fluorescence intensity at $575 \mathrm{~nm}\left(\mathrm{~F}_{515} / \mathrm{F}_{575}\right)$ for all samples. These plots (before, Figure 1C, and after, Figure 1D, normalization of baseline to 1 at time $t=0$, respectively) fully confirm that only the crotoxin sample displays a significant PLA2 activity, while with 
other protein samples, $\mathrm{CyaA}_{\mathrm{IP}}, \mathrm{CyaA}_{\mathrm{UBC}}$, or $\mathrm{BSA}$, the basal, random drifts of $\mathrm{F}_{515} / \mathrm{F}_{575}$ fluorescence ratio are indistinguishable from that recorded with the buffer alone or $60 \mathrm{mM}$ urea.

\subsection{PLA Activity Measurements as Monitored with the B3781 Fluorescent Probe}

We then investigated the PLA activity using the B3781 fluorescent probe that reports both PLA1 and PLA2 phospholipase activities (Figure 2). Fluorescence excitation was fixed at $342 \mathrm{~nm}$ and the emission spectra of the B3781 probe were recorded from 350 to $600 \mathrm{~nm}$ each minute for $30 \mathrm{~min}$ (see Figure S2). The 1-pyrenebutanoyl groups linked to the lipid acyl chains form excimers was characterized using a maximum fluorescence emission near $480 \mathrm{~nm}$. Hydrolysis of lipid acyl chains using a phospholipase releases a pyrene fatty acid that diffuses away from the pyrene lysophospholipid. These two pyrene derivatives exhibit a maximum emission of fluorescence between 380 and $400 \mathrm{~nm}[44,45]$.
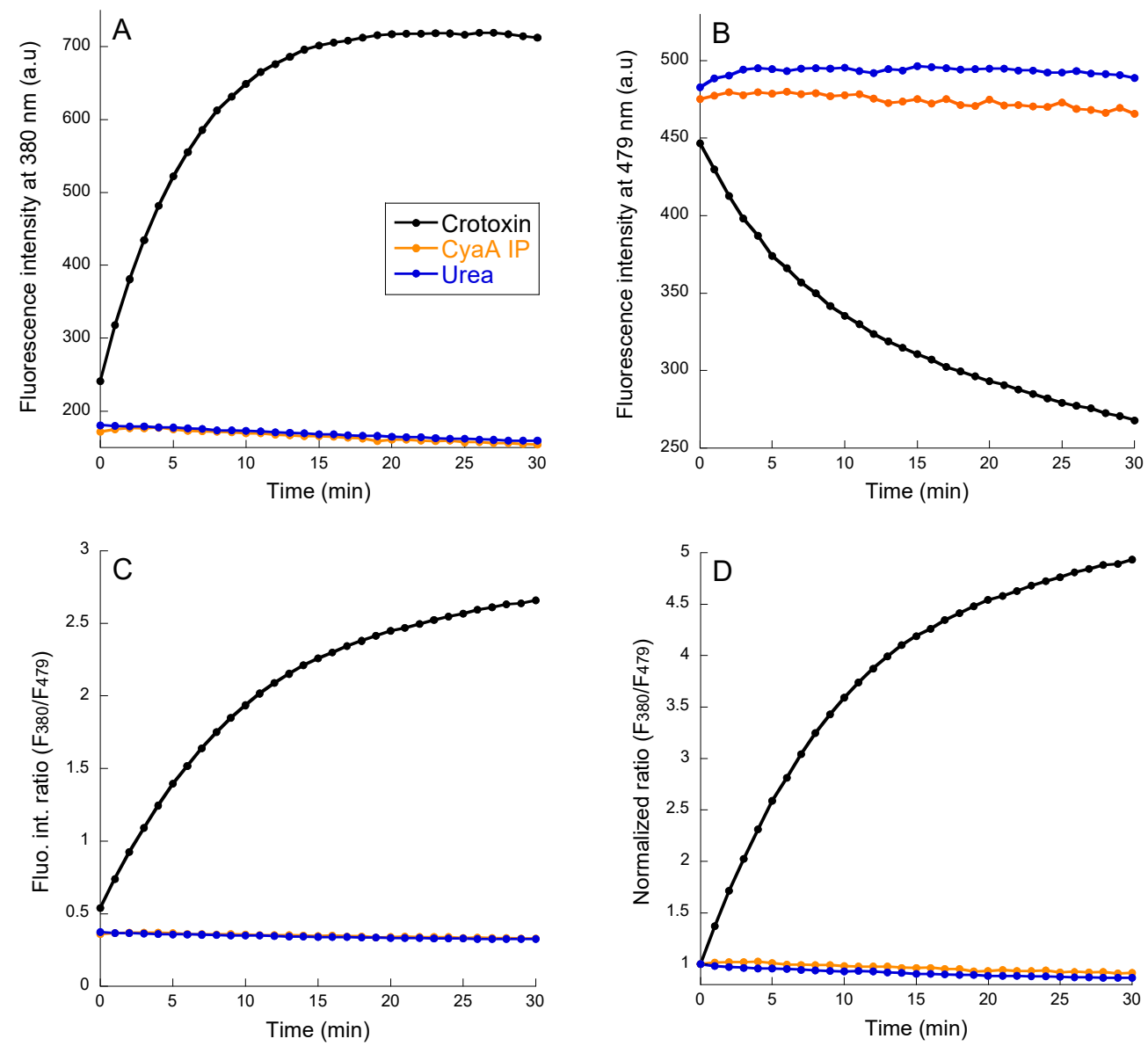

Figure 2. Kinetics of fluorescence changes of B3781 incorporated in POPC:POPG:B3781 79:20:1 LUV (data from Figure S2) upon addition of $100 \mathrm{nM}$ crotoxin (black), $600 \mathrm{nM} \mathrm{CyaA}$ IP (orange), and $180 \mathrm{mM}$ urea (dark blue). (A) Increase of fluorescence intensity emitted at $380 \mathrm{~nm}$. (B) Decrease of fluorescence emission intensity at $479 \mathrm{~nm}$. (C) Ratio of fluorescence intensity at $380 \mathrm{~nm}$ over fluorescence intensity at $479 \mathrm{~nm}: \mathrm{F}_{380} / \mathrm{F}_{479}$. (D) $\mathrm{F}_{380} / \mathrm{F}_{479}$ values are normalized to the initial $\mathrm{F}_{380} / \mathrm{F}_{479}$ value at $0 \mathrm{~min}$.

Figure 2 shows a time course recording of the fluorescence emission changes (at $380 \mathrm{~nm}, \mathrm{~F}_{380}$, Panel A, or 479 nm, F479, Panel B) of B3781 (in LUV composed of POPC:POPG:B3781 at a lipid ratio 79:20:1) after the addition of crotoxin, $\mathrm{CyaA}_{\mathrm{IP}}$, or urea $(180 \mathrm{mM}$ final concentration; full spectra are shown in Figure S2). Large changes in fluorescence, typical of excimer-to-monomer conversion of the B3781 probe, were observed with crotoxin $(100 \mathrm{nM})$ as a result of its PLA activity. However, no detectable changes were noticed with up to $600 \mathrm{nM}$ of purified CyaA, demonstrating the total 
lack of phospholipase activity of the toxin. Panels C and D in Figure 2 show the same results, as a ratio of fluorescence intensity at $380 \mathrm{~nm}$ over fluorescence intensity at $479 \mathrm{~nm}, \mathrm{~F}_{380} / \mathrm{F}_{479}$, before and after normalization to the initial $\mathrm{F}_{380} / \mathrm{F}_{479}$ value at a time of zero. All data representations clearly indicate that the CyaA toxin does not exhibit any detectable phospholipase A activity in these in vitro conditions.

\section{Discussion}

It is clear from our present data that no significant PLA1 or PLA2 activity can be detected for highly purified CyaA proteins using fluorescent probes classically used for measuring phospholipase A activity. These experiments were repeated several times, using several distinct CyaA batches, as well as different batches of LUV of different composition-in the absence (POPC:PED6 at 8:2 molar ratio) or in the presence of anionic lipids (POPC:POPG: B3781 at 79:20:1 molar ratio)—and different buffer conditions (Tris- $\mathrm{HCl}$ instead of HEPES-Na, data not shown). Our PLA assays were validated using crotoxin, a venom neurotoxin with potent PLA activity, and BSA as positive and negative controls, respectively. We therefore concluded that CyaA has no detectable PLA activity in vitro. These data corroborate the prior results found by Bumba et al. [40], who likewise could not detect PLA activity in their purified batches of CyaA.

Yet, how can these results be reconciled with the claims of the Ostolaza study? These authors used a similar fluorescent probe, PED1 to monitor the PLA1 activity of CyaA. In their reported experiments, only very small changes in fluorescent intensity of the probe $(<1.1-1.4$ relative ratio) were observed after the addition of CyaA. Moreover, the kinetic experiments presented in their recent paper [39] revealed odd profiles that question the validity of interpretation of the fluorescence changes as signatures of a PLA enzymatic activity. Indeed, they observed an abrupt, yet limited, change of fluorescence intensity just after addition of the CyaA sample (i.e., at the first recording point) with no further changes during the following $30 \mathrm{~min}$ of incubation. Strikingly, all assays at various concentrations of CyaA showed an identical profile: an abrupt initial change followed by a constant plateau over the whole course of the kinetics. Only the plateau values were different and roughly proportional to the amount of added proteins. Surprisingly, the authors were able to derive "velocities" (i.e., fluorescent change per minute) from these odd kinetic data, as shown in their plot of Figure 2C in [39].

The authors did notice the singular feature of the CyaA PLA activity. To explain this, as well as the very weak lipid hydrolytic activity as compared to that of other known phospholipases A, they proposed that a local accumulation of the lysophospholipidic product around the toxin molecules in the membrane could inhibit its PLA catalytic activity. Yet, it is hard to understand why the lysophospholipid could not continuously diffuse out in the membranes while being replaced by new substrates, i.e., unprocessed phospholipidic PLA probes. Furthermore, this hypothesis would require that the CyaA toxin binds to the lipid vesicles and hydrolyzes the PLA fluorescent probes within seconds after being added to the membrane with no further interaction and/or hydrolytic events occurring during the further $30 \mathrm{~min}$ of incubation. This is obviously not the case as all prior kinetic measurements of CyaA activities (including in prior publications from Ostolza and collaborators) clearly showed a progressive time-dependent accumulation of cAMP, hemolysis, or membrane permeabilization over a 5-30 min time scale. Therefore, it is more reasonable to assume that the weak and fast fluorescence increase observed by Gonzalez-Bullon et al. was an artifact, due to photon counting variations induced by light scattering as a result of the CyaA sample addition to the solution rather than to the consequence of a putative enzymatic cleavage of the probe by the PLA activity of CyaA. Indeed, in our experiments we did not observe any similar small burst of fluorescence after adding CyaA, but only a very limited random drift that was not different from that observed with the negative control BSA protein. In summary, on the basis of our in vitro assays with fluorescent PLA probes, we can unambiguously conclude that CyaA has no detectable PLA activity in vitro, which agrees with the prior studies of Bumba et al. [40]. 


\section{Material and Methods}

\subsection{Buffers}

Buffer $\mathrm{A}$ is composed of $20 \mathrm{mM}$ HEPES, $150 \mathrm{mM} \mathrm{NaCl}$ and $10 \mathrm{mM} \mathrm{CaCl}_{2} \mathrm{pH}$ 7.4. Buffer $\mathrm{B}$ is composed of $20 \mathrm{mM}$ HEPES, $150 \mathrm{mM} \mathrm{NaCl}$, and $2 \mathrm{mM} \mathrm{CaCl}_{2} \mathrm{pH} 7.4$.

\subsection{Protein Samples}

CyaA is expressed in E. coli, purified to homogeneity by established procedures [12,41]. CyaA was stored in $20 \mathrm{mM}$ HEPES, $6 \mathrm{M}$ urea, $\mathrm{pH}$ 7.4. CyaA was purified in our laboratory at Institut Pasteur and is hereafter called CyaA Ostolaza, from the University of Basque Country, hereafter named CyaA $A_{U B C}$. The crotoxin protein from Crotalus durissus terrificus is a kind gift from G. Faure [42,43]. Crotoxin was resuspended in $0.1 \%$ BSA in buffer B. BSA (from Sigma, St Louis, MI, USA, reference A0281) was resuspended in buffer B.

\subsection{Mass Spectrometry Analysis}

Sample Preparation

The protein digestion of the $\mathrm{CyaA}_{\mathrm{IP}}$ batch was performed as follows: CyaA was placed in $20 \mathrm{mM}$ HEPES, $6 \mathrm{M}$ in urea, and the $\mathrm{pH} 7.4$ was digested by Lys-C (V1671, Promega, Madison, WI, USA) at a Lys-C/CyaA ratio $1 / 50(\mathrm{w} / \mathrm{w})$, which corresponded to a $1 / 7 \mathrm{molar}$ ratio $(\mathrm{mol} / \mathrm{mol})$. The sample was vortexed and centrifuged for $1 \mathrm{~min}$ at $3000 \mathrm{rpm}$ then incubated for $3 \mathrm{~h}$ at $37^{\circ} \mathrm{C}$ under agitation (500 rpm). Urea concentration decreased to $2 \mathrm{M}$ with the addition of $20 \mathrm{mM}$ HEPES, which optimized trypsin digestion. Trypsin (V5111, Promega, Madison, WI, USA) was added at a trypsin/CyaA ratio of $1 / 50(\mathrm{w} / \mathrm{w})$. The sample was vortexed and centrifuged for $1 \mathrm{~min}$ at $3000 \mathrm{rpm}$ then the digestion was carried out for $1 \mathrm{~h}$ at $37^{\circ} \mathrm{C}$ under agitation (500 rpm). The digestion stopped with $2 \%$ formic acid (FA) (Fluka, 94318) and digested peptides were desalted on reversed phase $C_{18}$ Sep-Pak Cartridge (WAT054955, Waters Corporation, Milford, MA, USA). Peptides were eluted with a final 80\% Acetonitrile (ACN) $/ 0.1 \%$ Formic acid (FA). Resulting peptides were vacuum centrifuged to evaporate ACN and then lyophilized. Peptide samples were reconstituted in $2 \%$ ACN $/ 0.1 \%$ FA.

Protein digestion of the $\mathrm{Cya}_{\mathrm{UBC}}$ batch was performed as follows: $15 \mu \mathrm{g}$ of the purified fraction containing CyaA $\mathrm{ABC}_{\mathrm{UBC}}$ were diluted with Urea $8 \mathrm{M} / \mathrm{NH}_{4} \mathrm{HCO}_{3} 100 \mathrm{mM}$. The samples were reduced with $5 \mathrm{mM}$ TCEP over $1 \mathrm{~h}$ and alkylated with $20 \mathrm{mM}$ iodoacetamide over $1 \mathrm{~h}$. The sample was digested with rLys-C (Promega, Madison, WI, USA, V1671), ratio 1:50 (enzyme:protein/w:w) for $4 \mathrm{~h}$ at $37^{\circ} \mathrm{C}$ and then with Sequencing Grade Modified Trypsin (Promega, Madison, WI, USA, V5111), ratio 1:50 (enzyme:protein/w:w) overnight at $37^{\circ} \mathrm{C}$. The digestion stopped with $2 \%$ formic acid (FA) (Fluka, 94318) and digested peptides were purified with $C_{18}$ Spin Columns Pierce ${ }^{\mathrm{TM}}$ (ThermoFisher Scientific, Waltham, MA, USA, 89870). Peptides were eluted with $80 \%$ ACN $/ 0.1 \%$ FA. Resulting peptides were vacuum centrifuged to evaporate ACN and then lyophilized. Peptide samples were reconstituted in $2 \% \mathrm{ACN} / 0.1 \% \mathrm{FA}$.

\subsection{LC-MS/MS Analysis of the CyaA Batches}

LC-MS/MS analysis of the CyaA $\mathrm{A}_{\mathrm{IP}}$ batch was performed on a U3000-Velos mass spectrometer. A nanochromatographic system Ultimate 3000 system (Dionex, Amsterdam, The Netherlands) was coupled on-line to a LTQ-Orbitrap Velos Mass Spectrometer (Thermo Fisher Scientific, Waltham, MA, USA) using an integrated column oven (PRSO-V1, Sonation GmbH, Biberach, Germany). For each sample, $1.0 \mu \mathrm{g}$ of peptides were loaded onto a $\mathrm{C}_{18}$ pre-column $(300 \mu \mathrm{m}$ inner diameter $\times 5 \mathrm{~mm}$; Dionex, Sunnyvale, CA, USA) at $30 \mu \mathrm{L} / \mathrm{min}$ in $2 \% \mathrm{ACN}, 0.1 \%$ FA. After $5 \mathrm{~min}$ of desalting, the pre-column was switched online to an in-house packed $15 \mathrm{~cm}$ nano-HPLC column (75 $\mu \mathrm{m}$ inner diameter) with $\mathrm{C}_{18}$ resin (3 $\mu \mathrm{m}$ particles, 100 A pore size, ReproSil-Pur Basic C18, Dr. Maisch GmbH, Ammerbuch-Entringen, Germany). Peptides were then separated with a multi-step gradient from $2 \%$ to $9 \%$ buffer B (80\% 
$\mathrm{ACN} / 0.1 \% \mathrm{FA}$ ) in $5 \mathrm{~min}, 9 \%$ to $29 \%$ buffer B in $70 \mathrm{~min}, 29 \%$ to $56 \%$ buffer B in $30 \mathrm{~min}$, and $56 \%$ to $100 \%$ buffer B in $5 \mathrm{~min}$ at a flow rate of $300 \mathrm{~nL} / \mathrm{min}$ over $132 \mathrm{~min}$. The column temperature was set to $40{ }^{\circ} \mathrm{C}$. MS data were acquired using Xcalibur software with a survey scan (300-2000 m/z) analyzed into the Orbitrap mass analyzer at a resolution setting of 60,000, followed by $10 \mathrm{CID}$ fragmentations analyzed into the linear ion trap. The AGC targets for MS and MS/MS scans were set to 1E6 and 5E3 respectively. The isolation width was set to $2.5 \mathrm{~m} / \mathrm{z}$ and the normalized collision energy was set to 35 . Selected ions were dynamically excluded for $30 \mathrm{~s}$.

LC-MS/MS analysis of the CyaA $A_{U B C}$ batch was performed on a Proxeon 1200-Q Exactive mass spectrometer. A nanochromatographic system (Proxeon EASY-nLC 1200, Thermo Fisher Scientific, Waltham, MA, USA) was coupled on-line to a Q ExactiveTM Plus Mass Spectrometer (Thermo Fisher Scientific, Waltham, MA, USA) using an integrated column oven (PRSO-V1, Sonation GmbH, Biberach, Germany). For each samples, $1.0 \mu \mathrm{g}$ of peptides was injected onto a $46 \mathrm{~cm}$ homemade $\mathrm{C}_{18}$ column (1.9 $\mu \mathrm{m}$ particles, $100 \AA$ Å pore size, ReproSil-Pur Basic C18, Dr. Maisch GmbH, Ammerbuch-Entringen, Germany) and separated with a multi-step gradient from $2 \%$ to $7 \%$ buffer B ( $80 \%$ ACN $/ 0.1 \%$ FA) in $5 \mathrm{~min}, 7 \%$ to $23 \%$ buffer B in $70 \mathrm{~min}, 23 \%$ to $45 \%$ buffer B in $30 \mathrm{~min}$, and $45 \%$ to $95 \%$ buffer B in $5 \mathrm{~min}$ at a flow rate of $250 \mathrm{~nL} / \mathrm{min}$ over $132 \mathrm{~min}$. The column temperature was set to $60{ }^{\circ} \mathrm{C}$. MS data were acquired using Xcalibur software and a data-dependent Top 10 method with survey scans $(300-1700 \mathrm{~m} / \mathrm{z}$ ) at a resolution of 70,000 and a MS/MS scans (fixed first mass $100 \mathrm{~m} / \mathrm{z}$ ) at a resolution of 17,500. The AGC target and maximum injection time for the survey scans and the MS/MS scans were set to 3E6, $20 \mathrm{~ms}$, and 1E6, $60 \mathrm{~ms}$, respectively. The isolation window was set to $1.6 \mathrm{~m} / \mathrm{z}$ and normalized collision energy fixed to 28 for HCD fragmentation. We used a minimum AGC target of 1.0E4 for an intensity threshold of 1.7E5. Unassigned precursor ion charge states as well as 1, 7, 8 , and $>8$ charged states were rejecte and the peptide match was disabled. Excluded isotopes were enabled and selected ions were dynamically excluded for $45 \mathrm{~s}$.

\subsection{MaxQuant Analysis}

Raw data were analyzed using MaxQuant software version 1.5.1.2 [46] using the Andromeda search engine [47]. Based on the protein expression system, the MS/MS spectra were searched against the Escherichia coli strain BL21DE3 UniProt database containing 4,156 proteins plus the CyaA sequence. The digestion mode was set to trypsin and a maximum of two missed cleavages were allowed. N-terminal acetylation, Methionine oxidation, and Lysine $\mathrm{N}$-acylations (Myristoyl-4H, Myristoleylation, Myristoylation, Palmitoleylation, Palmitoylation) were set to variable modifications while Cystein Carbamidomethylation was set as fixed modification. The minimum peptide length was fixed to amino acids and the required false discovery rate was set to $1 \%$ at the PSM level and protein level. The main search peptide tolerance was set to $4.5 \mathrm{ppm}$ and to $0.5 \mathrm{Da}$ for the MS/MS match tolerance. Second peptide was enabled to identify co-fragmentation events.

\subsection{Fluorescent Probes}

PED6 (N-((6-(2,4-Dinitrophenyl)amino)hexanoyl)-2-(4,4-Difluoro-5,7-Dimethyl-4-Bora-3a, 4a-Diaza-s-Indacene-3-Pentanoyl)-1-Hexadecanoyl-sn-Glycero-3-Phosphoethanolamine, Triethylammonium Salt), and B3781 (1,2-Bis-(1-pyrenebutanoyl)-sn-glycero-3-phosphocholine) probes were purchased from Thermo Scientific. The PED6 and B3781 probes were resuspended in chloroform and stored at $-20^{\circ} \mathrm{C}$ under Argon.

\subsection{Preparation of PED6-Containing LUV}

Large unilamellar vesicles (LUV) were composed of DOPC:PED6 at a 8:2 molar ratio and prepared by reverse phase evaporation followed by extrusion of the multi-lamellar vesicles (MLV) suspension through $200 \mathrm{~nm}$ pore size polycarbonate filters [19]. A solution of $1 \mathrm{~mL}$ of LUVs was prepared at a lipid concentration of $500 \mu \mathrm{M}$ in buffer A. Size, polydispersity, and electrophoretic mobility of LUV suspensions were measured on a Zetasizer NanoZS (Malvern, UK). All proteins (CyaA samples, 
BSA, and crotoxin) were assayed for PLA activity at a final protein concentration of $10 \mathrm{nM}$. Lipid concentration of LUV in the cuvette was $10 \mu \mathrm{M}$, i.e., a lipid:protein molar ratio of 1000. Experiments were performed under constant stirring at $37{ }^{\circ} \mathrm{C}$ using a $109004 \mathrm{~F}$ cuvette (Hellma) in a Jasco fluorometer. Fluorescence excitation was fixed at $480 \mathrm{~nm}$ and the emission spectra were recorded from 490 to $650 \mathrm{~nm}$ each minute for $30 \mathrm{~min}$. The 2,4-Dinitrophenyl group linked on the lipid headgroup does quench the 4,4-Difluoro-5,7-Dimethyl-4-Bora-3a,4a-Diaza-s-Indacene group linked to the acyl chain. PLA2 activity will allow fluorescence recovery of the indacene derivative released in the membrane and diffusing away from the 2,4-Dinitrophenyl group liked to the lysophospholipid.

\subsection{Preparation of B3781-Containing LUV}

Large unilamellar vesicles (LUV) were composed of POPC:POPG:B3781 at a 79:20:1 molar ratio and prepared by reverse phase evaporation followed by extrusion of the multi-lamellar vesicles (MLV) suspension through $200 \mathrm{~nm}$ pore size polycarbonate filters [19]. A solution of $2 \mathrm{~mL}$ of LUVs was prepared at a lipid concentration of $2 \mathrm{mM}$ in buffer B. Size, polydispersity, and electrophoretic mobility of LUV suspensions were measured on a Zetasizer NanoZS (Malvern). CyaA and crotoxin were assayed for PLA activity at a final protein concentration of $600 \mathrm{nM}$ and $100 \mathrm{nM}$, respectively. Lipid concentration of LUV in the cuvette was $200 \mu \mathrm{M}$, i.e., a lipid:protein molar ratio of 333 for CyaA and 2000 for crotoxin. Experiments were performed under constant stirring at $37^{\circ} \mathrm{C}$ using a $109004 \mathrm{~F}$ cuvette (Hellma) in a Jasco fluorometer. Fluorescence excitation was fixed at $342 \mathrm{~nm}$ and the emission spectra were recorded from 350 to $600 \mathrm{~nm}$ each minute for $30 \mathrm{~min}$. The 1-pyrenebutanoyl groups linked to the lipid acyl chains form excimers characterized by a maximum emission of fluorescence near $480 \mathrm{~nm}$. Hydrolysis of acyl chains by a phospholipase releases a pyrene fatty acid that diffuses away from the pyrene lysophospholipd. These two pyrene derivatives exhibit a maximum emission of fluorescence between 380 and $400 \mathrm{~nm}[44,45]$.

Supplementary Materials: The following are available online at http:/ / www.mdpi.com/2072-6651/11/2/111/s1, The supporting information contains two figures and two files that report the lists of the contaminant proteins identified by mass spectrometry in the IP CyaA samples, CyaA IP, CyaA_IP_MS_result, and in the UBC CyaA sample, CyaA ${ }_{U B C}$, CyaA_UBC_MS_result.

Author Contributions: Conceptualization, D.L. and A.C.; methodology, A.V., M.M., D.L. and A.C.; validation, M.M. and A.C.; investigation, A.V., M.S., D.R.-B. and T.D.; data curation, A.V. and T.D.; writing-original draft preparation, A.C.; writing-review and editing, A.V., D.L. and A.C.; visualization, A.V.; supervision, A.C.; project administration, A.C.

Funding: A.V. was supported by a DIM MalInf (infectious diseases) grant. M.S. was supported by the Erasmus+ program from the European Commission. We thank the CACSICE Equipex ANR-11-EQPX-0008. This research was funded by Institut Pasteur and CNRS. The APC was funded by Institut Pasteur.

Acknowledgments: We thank Helena Ostolaza for sharing her biological material, the CyaAUBC sample, and G. Faure for providing us purified crotoxin.

Conflicts of Interest: The authors declare no competing interests.

\section{References}

1. Ladant, D.; Brezin, C.; Alonso, J.M.; Crenon, I.; Guiso, N. Bordetella pertussis adenylate cyclase. Purification, characterization, and radioimmunoassay. J. Biol. Chem. 1986, 261, 16264-16269. [PubMed]

2. Glaser, P.; Danchin, A.; Ladant, D.; Barzu, O.; Ullmann, A. Bordetella pertussis adenylate cyclase: The gene and the protein. Tokai J. Exp. Clin. Med. 1988, 13, 239-252. [PubMed]

3. Glaser, P.; Ladant, D.; Sezer, O.; Pichot, F.; Ullmann, A.; Danchin, A. The calmodulin-sensitive adenylate cyclase of Bordetella pertussis: Cloning and expression in Escherichia coli. Mol. Microbiol. 1988, 2, 19-30. [CrossRef] [PubMed]

4. Guiso, N. Bordetella Adenylate Cyclase-Hemolysin Toxins. Toxins 2017, 9, 277. [CrossRef] [PubMed]

5. Novak, J.; Cerny, O.; Osickova, A.; Linhartova, I.; Masin, J.; Bumba, L.; Sebo, P.; Osicka, R. Structure-Function Relationships Underlying the Capacity of Bordetella Adenylate Cyclase Toxin to Disarm Host Phagocytes. Toxins 2017, 9, 300. [CrossRef] [PubMed] 
6. Coote, J.G. Structural and functional relationships among the RTX toxin determinants of gram-negative bacteria. FEMS Microbiol. Rev. 1992, 8, 137-161. [CrossRef]

7. Welch, R.A. RTX toxin structure and function: A story of numerous anomalies and few analogies in toxin biology. Curr. Top. in Microbiol. and Immunol. 2001, 257, 85-111.

8. Linhartova, I.; Bumba, L.; Masin, J.; Basler, M.; Osicka, R.; Kamanova, J.; Prochazkova, K.; Adkins, I.; Hejnova-Holubova, J.; Sadilkova, L.; et al. RTX proteins: A highly diverse family secreted by a common mechanism. FEMS Microbiol. Rev. 2010, 34, 1076-1112. [CrossRef] [PubMed]

9. Chenal, A.; Sotomayor Perez, A.C.; Ladant, D. Structure and function of RTX Toxins. In The Comprehensive Sourcebook of Bacterial Protein Toxins, 4th ed.; Elsevier: Amsterdam, The Netherlands, 2015.

10. Benz, R. Channel formation by RTX-toxins of pathogenic bacteria: Basis of their biological activity. Biochim. Biophys. Acta. 2016, 1858, 526-537. [CrossRef] [PubMed]

11. Ladant, D.; Ullmann, A. Bordatella pertussis adenylate cyclase: A toxin with multiple talents. Trends Microbiol. 1999, 7, 172-176. [CrossRef]

12. Karst, J.C.; Ntsogo Enguene, V.Y.; Cannella, S.E.; Subrini, O.; Hessel, A.; Debard, S.; Ladant, D.; Chenal, A. Calcium, Acylation, and Molecular Confinement Favor Folding of Bordetella pertussis Adenylate Cyclase CyaA Toxin into a Monomeric and Cytotoxic Form. J. Biol. Chem. 2014, 289, 30702-30716. [CrossRef] [PubMed]

13. Ladant, D. Interaction of Bordetella pertussis adenylate cyclase with calmodulin. Identification of two separated calmodulin-binding domains. J. Biol. Chem. 1988, 263, 2612-2618. [PubMed]

14. Karst, J.C.; Sotomayor Perez, A.C.; Guijarro, J.I.; Raynal, B.; Chenal, A.; Ladant, D. Calmodulin-induced conformational and hydrodynamic changes in the catalytic domain of Bordetella pertussis adenylate cyclase toxin. Biochemistry 2010, 49, 318-328. [CrossRef] [PubMed]

15. O’Brien, D.P.; Durand, D.; Voegele, A.; Hourdel, V.; Davi, M.; Chamot-Rooke, J.; Vachette, P.; Brier, S.; Ladant, D.; Chenal, A. Calmodulin fishing with a structurally disordered bait triggers CyaA catalysis. PLoS Biol. 2017, 15, e2004486. [CrossRef]

16. Karst, J.C.; Barker, R.; Devi, U.; Swann, M.J.; Davi, M.; Roser, S.J.; Ladant, D.; Chenal, A. Identification of a region that assists membrane insertion and translocation of the catalytic domain of Bordetella pertussis CyaA toxin. J. Biol. Chem. 2012, 287, 9200-9212. [CrossRef] [PubMed]

17. Subrini, O.; Sotomayor-Perez, A.C.; Hessel, A.; Spiaczka-Karst, J.; Selwa, E.; Sapay, N.; Veneziano, R.; Pansieri, J.; Chopineau, J.; Ladant, D.; et al. Characterization of a membrane-active peptide from the Bordetella pertussis CyaA toxin. J. Biol. Chem. 2013, 288, 32585-32598. [CrossRef] [PubMed]

18. Masin, J.; Osickova, A.; Sukova, A.; Fiser, R.; Halada, P.; Bumba, L.; Linhartova, I.; Osicka, R.; Sebo, P. Negatively charged residues of the segment linking the enzyme and cytolysin moieties restrict the membrane-permeabilizing capacity of adenylate cyclase toxin. Sci. Rep. 2016, 6, 29137. [CrossRef] [PubMed]

19. Voegele, A.; Subrini, O.; Sapay, N.; Ladant, D.; Chenal, A. Membrane-Active Properties of an Amphitropic Peptide from the CyaA Toxin Translocation Region. Toxins 2017, 9, 369. [CrossRef]

20. Knapp, O.; Maier, E.; Masin, J.; Sebo, P.; Benz, R. Pore formation by the Bordetella adenylate cyclase toxin in lipid bilayer membranes: Role of voltage and pH. Biochim. Biophys. Acta 2008, 1778, 260-269. [CrossRef]

21. Basler, M.; Knapp, O.; Masin, J.; Fiser, R.; Maier, E.; Benz, R.; Sebo, P.; Osicka, R. Segments crucial for membrane translocation and pore-forming activity of Bordetella adenylate cyclase toxin. J. Biol. Chem. 2007, 282, 12419-12429. [CrossRef]

22. Barry, E.M.; Weiss, A.A.; Ehrmann, I.E.; Gray, M.C.; Hewlett, E.L.; Goodwin, M.S. Bordetella pertussis adenylate cyclase toxin and hemolytic activities require a second gene, cyaC, for activation. J. Bacteriol. 1991, 173, 720-726. [CrossRef]

23. Hackett, M.; Guo, L.; Shabanowitz, J.; Hunt, D.F.; Hewlett, E.L. Internal lysine palmitoylation in adenylate cyclase toxin from Bordetella pertussis. Science 1994, 266, 433-435. [CrossRef] [PubMed]

24. Westrop, G.D.; Hormozi, E.K.; Da Costa, N.A.; Parton, R.; Coote, J.G. Bordetella pertussis adenylate cyclase toxin: proCyaA and CyaC proteins synthesised separately in Escherichia coli produce active toxin in vitro. Gene 1996, 180, 91-99. [CrossRef]

25. Veneziano, R.; Rossi, C.; Chenal, A.; Devoisselle, J.M.; Ladant, D.; Chopineau, J. Bordetella pertussis adenylate cyclase toxin translocation across a tethered lipid bilayer. Proc. Natl. Acad. Sci. USA 2013, 110, 20473-20478. [CrossRef] [PubMed] 
26. Rose, T.; Sebo, P.; Bellalou, J.; Ladant, D. Interaction of calcium with Bordetella pertussis adenylate cyclase toxin. Characterization of multiple calcium-binding sites and calcium-induced conformational changes. J. Biol. Chem. 1995, 270, 26370-26376. [CrossRef]

27. Chenal, A.; Guijarro, J.I.; Raynal, B.; Delepierre, M.; Ladant, D. RTX calcium binding motifs are intrinsically disordered in the absence of calcium: Implication for protein secretion. J. Biol. Chem. 2009, 284, 1781-1789. [CrossRef] [PubMed]

28. Sotomayor Perez, A.C.; Karst, J.C.; Davi, M.; Guijarro, J.I.; Ladant, D.; Chenal, A. Characterization of the regions involved in the calcium-induced folding of the intrinsically disordered RTX motifs from the bordetella pertussis adenylate cyclase toxin. J. Mol. Biol. 2010, 397, 534-549. [CrossRef] [PubMed]

29. Chenal, A.; Karst, J.C.; Sotomayor Perez, A.C.; Wozniak, A.K.; Baron, B.; England, P.; Ladant, D. Calcium-induced folding and stabilization of the intrinsically disordered RTX domain of the CyaA toxin. Biophys. J. 2010, 99, 3744-3753. [CrossRef] [PubMed]

30. Sotomayor-Perez, A.C.; Ladant, D.; Chenal, A. Calcium-induced folding of intrinsically disordered repeat-in-toxin (RTX) motifs via changes of protein charges and oligomerization states. J. Biol. Chem. 2011, 286, 16997-17004. [CrossRef] [PubMed]

31. Sotomayor-Perez, A.C.; Subrini, O.; Hessel, A.; Ladant, D.; Chenal, A. Molecular Crowding Stabilizes Both the Intrinsically Disordered Calcium-Free State and the Folded Calcium-Bound State of a Repeat in Toxin (RTX) Protein. J. of the Am. Chem. Soc. 2013, 135, 11929-11934. [CrossRef]

32. Sotomayor-Perez, A.C.; Ladant, D.; Chenal, A. Disorder-to-order transition in the CyaA toxin RTX domain: Implications for toxin secretion. Toxins 2015, 7, 1-20. [CrossRef] [PubMed]

33. O’Brien, D.P.; Hernandez, B.; Durand, D.; Hourdel, V.; Sotomayor-Perez, A.C.; Vachette, P.; Ghomi, M.; Chamot-Rooke, J.; Ladant, D.; Brier, S.; et al. Structural models of intrinsically disordered and calcium-bound folded states of a protein adapted for secretion. Sci. Rep. 2015, 5, 14223. [CrossRef] [PubMed]

34. Bumba, L.; Masin, J.; Macek, P.; Wald, T.; Motlova, L.; Bibova, I.; Klimova, N.; Bednarova, L.; Veverka, V.; Kachala, M.; et al. Calcium-Driven Folding of RTX Domain beta-Rolls Ratchets Translocation of RTX Proteins through Type I Secretion Ducts. Mol. Cell 2016, 62, 47-62. [CrossRef] [PubMed]

35. O’Brien, D.P.; Perez, A.C.S.; Karst, J.; Cannella, S.E.; Enguene, V.Y.N.; Hessel, A.; Raoux-Barbot, D.; Voegele, A.; Subrini, O.; Davi, M.; et al. Calcium-dependent disorder-to-order transitions are central to the secretion and folding of the CyaA toxin of Bordetella pertussis, the causative agent of whooping cough. Toxicon 2018, 149, 37-44. [CrossRef] [PubMed]

36. El-Azami-El-Idrissi, M.; Bauche, C.; Loucka, J.; Osicka, R.; Sebo, P.; Ladant, D.; Leclerc, C. Interaction of Bordetella pertussis adenylate cyclase with CD11b/CD18: Role of toxin acylation and identification of the main integrin interaction domain. J. Biol. Chem. 2003, 278, 38514-38521. [CrossRef] [PubMed]

37. Fedele, G.; Schiavoni, I.; Adkins, I.; Klimova, N.; Sebo, P. Invasion of Dendritic Cells, Macrophages and Neutrophils by the Bordetella Adenylate Cyclase Toxin: A Subversive Move to Fool Host Immunity. Toxins 2017, 9, 293. [CrossRef] [PubMed]

38. Gonzalez-Bullon, D.; Uribe, K.B.; Martin, C.; Ostolaza, H. Phospholipase A activity of adenylate cyclase toxin mediates translocation of its adenylate cyclase domain. Proc. Natl. Acad. Sci. USA 2017, 114, E6784-E6793. [CrossRef] [PubMed]

39. Gonzalez-Bullon, D.; Martin, C.; Ostolaza, H. Characterization of the Intrinsic Phospholipase A1 Activity of Bordetella pertussis Adenylate Cyclase Toxin. Toxins 2018, 10, 514. [CrossRef] [PubMed]

40. Bumba, L.; Masin, J.; Osickova, A.; Osicka, R.; Sebo, P. Bordetella Pertussis Adenylate Cyclase Toxin Does Not Possess a Phospholipase A Activity; Serine 606 and Aspartate 1079 Residues Are Not Involved in Target Cell Delivery of the Adenylyl Cyclase Enzyme Domain. Toxins 2018, 10, 245. [CrossRef]

41. Cannella, S.E.; Ntsogo Enguene, V.Y.; Davi, M.; Malosse, C.; Sotomayor Perez, A.C.; Chamot-Rooke, J.; Vachette, P.; Durand, D.; Ladant, D.; Chenal, A. Stability, structural and functional properties of a monomeric, calcium-loaded adenylate cyclase toxin, CyaA, from Bordetella pertussis. Sci. Rep. 2017, 7, 42065. [CrossRef]

42. Ostrowski, M.; Porowinska, D.; Prochnicki, T.; Prevost, M.; Raynal, B.; Baron, B.; Sauguet, L.; Corringer, P.J.; Faure, G. Neurotoxic phospholipase A2 from rattlesnake as a new ligand and new regulator of prokaryotic receptor GLIC (proton-gated ion channel from G. violaceus). Toxicon 2016, 116, 63-71. [CrossRef] [PubMed]

43. Hendrickson, H.S.; Rauk, P.N. Continuous fluorometric assay of phospholipase A2 with pyrene-labeled lecithin as a substrate. Anal. Biochem. 1981, 116, 553-558. [CrossRef] 
44. Cox, J.; Mann, M. MaxQuant enables high peptide identification rates, individualized p.p.b.-range mass accuracies and proteome-wide protein quantification. Nat. Biotechnol. 2008, 26, 1367-1372. [CrossRef] [PubMed]

45. Faure, G.; Xu, H.; Saul, F.A. Crystal structure of crotoxin reveals key residues involved in the stability and toxicity of this potent heterodimeric beta-neurotoxin. J. Mol. Bio. 2011, 412, 176-191. [CrossRef] [PubMed]

46. Aarsman, A.J.; Vandeenen, L.L.M.; Vandenbosch, H. Studies on Lysophospholipases VII. Synthesis of Acylthioester Analogs of Lysolecithin and Their Use in a Continuous Spectrophotometric Assay for Lysophospholipases, a Method with Potential Applicability to Other Lipolytic Enzymes. Bioorg. Chem. 1976, 5, 241-253. [CrossRef]

47. Cox, J.; Neuhauser, N.; Michalski, A.; Scheltema, R.A.; Olsen, J.V.; Mann, M. Andromeda: A peptide search engine integrated into the MaxQuant environment. J. Proteome Res. 2011, 10, 1794-1805. [CrossRef] [PubMed]

2019 by the authors. Licensee MDPI, Basel, Switzerland. This article is an open access article distributed under the terms and conditions of the Creative Commons Attribution (CC BY) license (http:/ / creativecommons.org/licenses/by/4.0/). 